\title{
Computer science and technology in India: A critical assessment
}

\author{
R NARASIMHAN and P V S RAO \\ Tata Institute of Fundamental Research, Homi Bhabha Road, Bombay 400005, India
}

\begin{abstract}
Information technology, which has as its base the integration of computing and communication, is bringing about far-reaching changes in the economies and life-styles of the advanced industrialized countries. In India, the preoccupation so far has been in the development of computer technology to manufacture stand-alone computers. Even to accomplish this the industrial capability is very fragmented. The mastery of information technology in all its ramifications requires building up indigenous capabilities in a variety of sub-technologies. In this context, this paper analyses in some detail the current strengths and weaknesses in computer science and technology in India and the efforts that need to be made to build up a viable base in information technology to promote economic growth and modernize industrial practices.
\end{abstract}

Keywords. Computer science and technology; information technology; information economy; indigenous capability; laboratory machines; microprocessor-based machines; system building; manpower development; public education.

\section{Introduction: Scope of the paper}

The first electronic digital computer-ENIAC-was commissioned for use in the early 1940s. In less than half a century, computer technology in the West has gone through four generations of development and talk about fifth generation computers is very much in the air today: (see table 1 for a characterization of the 'generations'). From another point of view, computers, which started out as stand-alone, 'numbercrunching' and commercial data-processing systems, have during this period become all-pervasive 'engines' that are transforming the Western Societies into 'information societies' and Western economies into 'information economies'. It is important to understand the nature of these far-reaching changes and the technological and market forces that have been instrumental in bringing about these changes. It is only within such a broad framework-relating information processing science, technology and industry, and considering their effects on society and economy-that one can properly assess the current status of computer science and technology in India and the effectiveness of the role they are playing in growing an information industry and in transforming the Indian society into an information-conscious one. From the gaps and shortfalls in current endeavours one should be able to identify actions that need to be taken to realize the full benefits of this technology.

In an early effort at an analysis of the problems and prospects of the applications of computers to development by developing countries, a un Expert Group suggested four levels of classification of countries according to their computer awareness and usage. The levels were termed: initial, basic, operational and advanced. Table 2 summarizes the characterizing features of these levels. If one analyses the levels of computer awareness, literacy, usage, and mastery of the technology in India with reference to this 


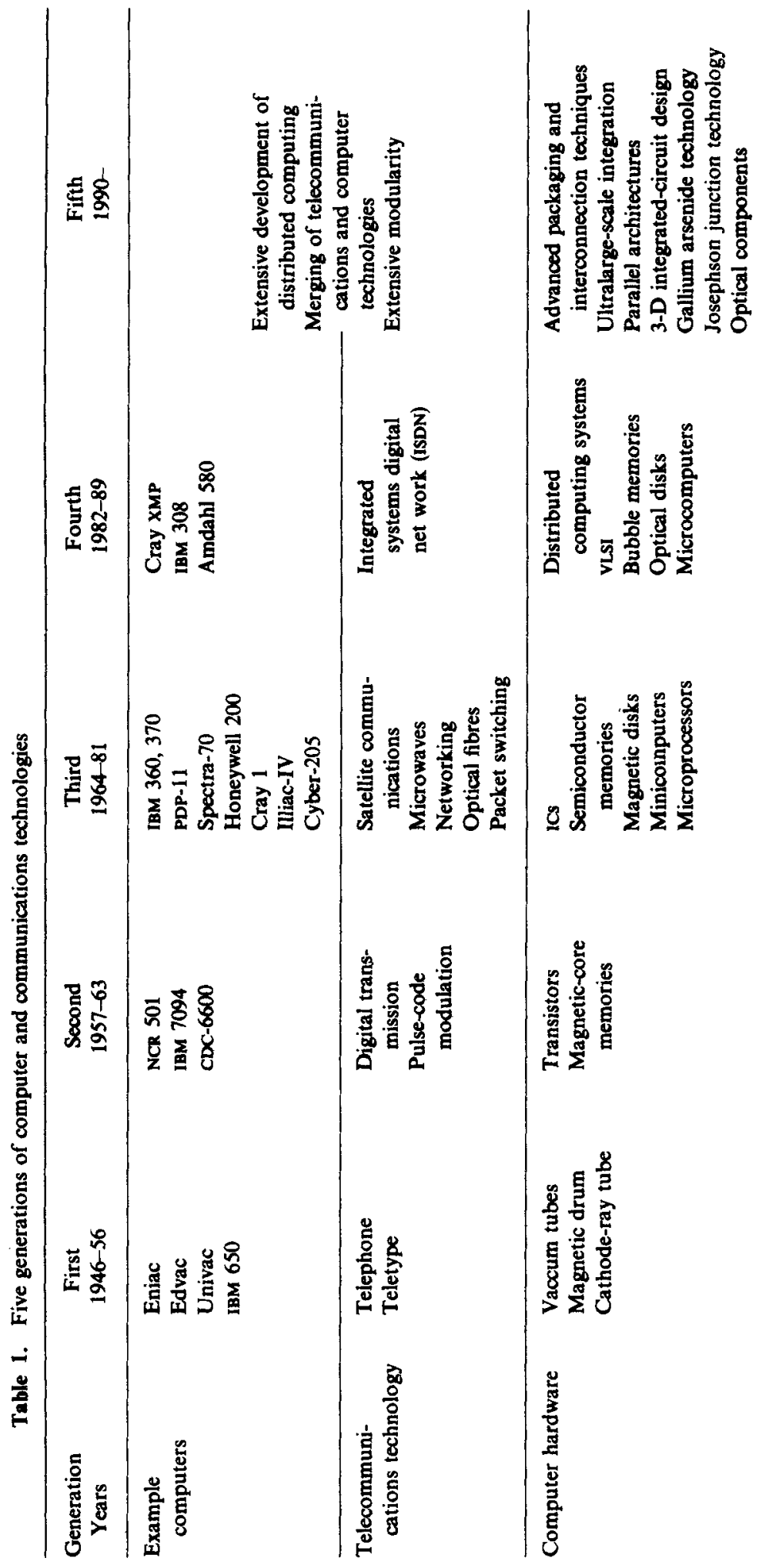




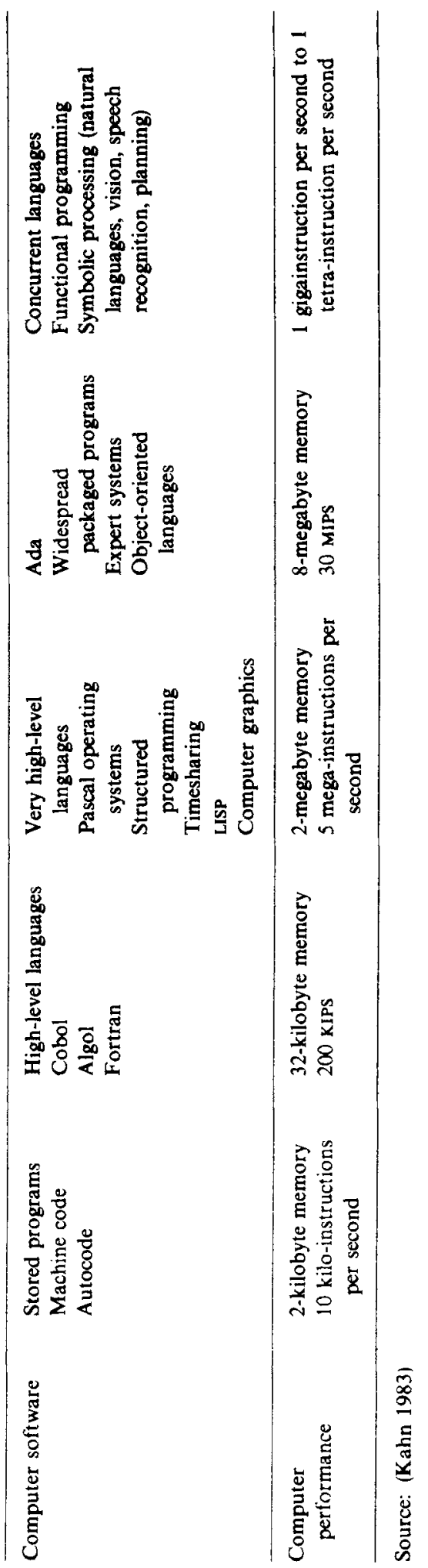


Table 2. Levels of computer usage

\begin{tabular}{|c|c|}
\hline Level & Characteristics \\
\hline Initial & $\begin{array}{l}\text { There are no operational computers in the country. A few nationals have } \\
\text { had contact with computing. The only local sources of information are } \\
\text { computer salesmen. }\end{array}$ \\
\hline Basic & $\begin{array}{l}\text { There is some understanding of computers in government (and private) } \\
\text { decision centres. A few computer installations are to be found. There are } \\
\text { some nationals involved in computer operations. There is some oduca- } \\
\text { tion and training in computer technology in the country. Computers are } \\
\text { used in basic government operations. }\end{array}$ \\
\hline Operational & $\begin{array}{l}\text { There is extensive understanding of computers in government (and } \\
\text { private) decision centres. Among the numerous computer installations } \\
\text { there are some very large machines. There are centres for education and } \\
\text { training in computer technology and some are of excellent quality. They } \\
\text { offer degree programmes in computer or information science. There is } \\
\text { design and production of software and some manufacture of hardware. } \\
\text { Computers are affecting many disciplines, particularly science, engineer- } \\
\text { ing, and medicine. }\end{array}$ \\
\hline Advanced & $\begin{array}{l}\text { Most government and administrative work is carried out by computers. } \\
\text { There are well established professional activities and national meetings } \\
\text { on computers. There is a complete range of quality education and } \\
\text { training programmes. The number of computers, of all sizes, is } \\
\text { increasing rapidly. Time-sharing, teleprocessing, and remote job entry } \\
\text { are common. There is design and production of both hardware and } \\
\text { software. Many technologies have been changed or are in the course of } \\
\text { being changed. New applications of computers are found regularly. } \\
\text { There is strong participation in and contribution to international } \\
\text { activities. }\end{array}$ \\
\hline
\end{tabular}

(Source: United Nations 1971)

table, one would find that the levels prevailing in India span the entire spectrum described in the table - from the initial to the advanced. There are centres for education and training in computer science and technology in India and some of these are of excellent quality. There are well-established professional activities and national meetings on computers and computing. There is some manufacture of hardware and there exists application software generation capability of high quality and sophistication in some areas. Institutionalised frameworks have been created in the country to provide computing access to software entrepreneurs and others, and also to provide maintenance and other support services to end-users of imported computers. Resource groups have demonstrated their capability to engage in software technology generation and spin-off at the leading edge of this technology. Capability to build customized systems for complex real-time applications has been impressively demonstrated. Software generation capability has also been built up in a limited way to compete successfully in the international export market.

All this notwithstanding, the general status of computer science and technology in India can only be described as patchy and unsatisfactory. There is very little penetration of computer literacy in government and private decision centres. Computer literacy is not part of the general educational curriculum of the vast majority of college-level students, not to mention high school and vocational school students. To a very large extent information processing needs are still met through ad hoc imports. There are still 
very few software companies or third party consultancy agencies providing effective assistance to end-users in the country. Apart from the government sector, there are vast areas of the economy of extreme importance to development that continue to function in the pre-computer age. This is especially true of almost the entire service sector. The single most important reason for this is the wholly underdeveloped status of the data communication technology and infrastructure in India.

What one should like to be able to do is to work out policies, programmes, and institutions to build on our available and demonstrated strength in order to remove progressively the existing weaknesses in the areas of computer science and technology. But this is a formidable task and it would take us too far outside the scope of this paper to attempt this in any systematic manner here. We shall rather focus on a limited set of issues.

In the next section a brief sketch is given of the present status of computer and information technology in the advanced industrialised countries and the way it is transforming the industrial base and economies of these countries. As noted earlier it is against this backdrop that the potentials of computer technology for our own internal use could be meaningfully assessed and effective action programmes to realise these potentials worked out.

In $\$ 3$, in the context of high-priority strategic and development-catalysing sectors where computer technology should be applied, some plausible methodologies are discussed. These are based on lessons that could be drawn from successful collaborations between end-users, R\&D establishments and manufacturing groups to design, fabricate and commission for field-level use complex, customised, computer-based systems. Some current weaknesses in the hardware manufacturing industrial base are identified and options available for overcoming these are discussed.

In realising the full potential of computer and information technology, manpower is the most critical resource. The current status of this resource in India and ways to enhance its availability are discussed in $\$ 4$.

From the long term viewpoint it is of the utmost importance to ensure that leadership is built up and maintained in teaching and academic research in the frontier areas of computer science-in hardware, software, applications and theory. In $\$ 5$ trends in these areas are considered and in the light of existing gaps and weaknesses in the country, suggestions are made for systematic programmes to be undertaken.

Section 6 summarises our views on the steps to be taken to strengthen the status of computer science and technology activity in India.

\section{Information technology and the information economy}

Information transacted in a market "enables the consumer to know something that was not known beforehand; to exchange a symbolic experience; to learn or relearn something; to change perception or cognition; to reduce uncertainty; to expand one's range of options; to exercise rational choice: to evaluate decisions; to control a process; to communicate an idea, a fact, or an opinion" (Porat 1977). Information activities are concerned with creating (gathering, producing), processing (packaging, transforming, analysing), or distributing (educating, communicating) information of relevance to the end-usages described above. Information goods are products (materials, equipment, systems, buildings) that support information activities. Performing information 
activities, or producing, operating, maintaining information goods, constitute information occupations. The information sector is made up of all the information occupations in an economy. In all $O E C D$ countries, the contribution of the information sector to the GNP has been growing (OECD 1982).

Information technology that underpins information occupations in the advanced industrialized countries has been undergoing a radical transformation due to the coming together of computer and communication technologies. These, as recently as a decade ago, were developing independently of each other. The integration of these two technologies has been made possible, of course, through spectacular developments in microelectronics such as integration of hundreds of thousands of logic circuits on single microchips, major developments in laser, printing and display technologies, the use of fibre-optics and satellites in communications, and through basic innovations in the deployment of software technology. The impact of these technologies is already beginning to be felt on manufacturing and service industries in terms of their structure and content, and on employment and skill requirements in information occupations. In decades to come their impact is bound to be even more radical. It is important to become aware of the relevance of some of the basic implications of these technologies to the Indian industrial and economic scene.

Integrated circuit technology is making major changes in the production process of consumer durables. The number of components per unit product is being drastically reduced over a wide range of goods. One silicon chip in an electronic sewing machine replaced 350 standard parts. There have been similar effects on the production of colour Tv sets, teleprinters, printing equipment, and other items. The overall results have been the simplification of product design, increased automation of the production process, improved quality of performance, simplification of maintenance, and reduction in cost of production. Relatively small production runs (for example, under 5000 units) are becoming economically viable.

In the service sector, retail traders are inceasingly using point-of-sales terminals, and automated warehousing and inventory control through optical character recognition techniques. Automated methods of handling paper-based transactions and electronic funds transfer systems are being introduced in the financial sector operations. Computer-assisted publishing, data-banks for legal and medical services, electronic scanning and analysis techniques for medical diagnosis, computer-aided design systems for design, layout and drafting, are some of the other innovations that are beginning to be routinely adopted. The office environment, that has traditionally been one of undercapitalization and low productivity, is under tremendous pressure to change through the use of information technology.

Applications of information technology have given rise to new products-both capital and consumer goods. In the former category are numerically-controlled machines and word-processors. In the latter category are electronic watches, home computers, educational toys, video-games, etc.

Innovations within the technologies based on microelectronics-lasers, printing and display technologies, optical fibres, satellites and software- have been largely centrifugal in nature. That is, they encourage vertical disintegration and decentralised and fragmented production. By reducing the scale for optimal operation, they lower fixed and working costs and make it easier for new entrepreneurs to enter these fields.

Digital transmission technology promises to be potentially the single most innovative and industrially rewarding technology. By combining together in the most 
imaginative manner various facets of information technology (microprocessors, fibreoptics, vLSI, satellites, specialized software for real-time and database applications), it is becoming possible to transmit voice, data, TV, radio, and other communications through a single medium with equal facility and without expensive conversions. Centrifugal tendencies are already evident in OECD countries in providing terminal equipment to public-switched networks and in providing a variety of innovative network services themselves.

There are many lessons of direct relevance to the Indian scene that can be drawn from these radical industrial and economic changes that are taking place in the advanced, industrialised countries. The first and the most important one is the need to become aware of information as an economic commodity, and of information technology as one with a great potential for income-creation and modernization.

Information technology allows certain kinds of skills to be transferred from a worker to a machine. Instead of negatively assessing this feature as one of deskilling, in the Indian context we should try to derive benefits from "intelligent" machines which could be used to increase productivity although operated by lower-skilled workers. The relatively low capital cost of such machines should enable the deployment of more of these machines to increase employment and production.

Another important feature of information technology is its intimate relationship to the service sector. Services of all kinds are extremely undeveloped in India. Imaginative deployment of information technology to bring high-quality professional and technical services within the reach of the service-starved millions in the districts and rural areas is an urgent necessity. There is tremendous scope for innovative entrepreneurship in accomplishing this.

The status of computer technology in India must be assessed, as earlier emphasized, in this larger context of its role in the creation of a wide base for the deployment of information technology for purposes of development and modernization. Manufacture of computers for stand-alone use is only a small facet of this more global need. The real challenge is to build up the capability to design, fabricate and operate computer-based systems to manage, monitor, control, and otherwise support a whole variety of activities in the field, in the design room, in the production shop, in the office, and in all kinds of services. What is the current status of our design knowhow to design such systems? What is the current status of our technological and manufacturing base to produce such systems? What is, finally, the status of our manpower resources to absorb and use such systems in a productive manner? In the following sections we shall briefly discuss these issues.

\section{Indigenous capability in design and manufacture}

\subsection{Growth of manufacturing capability}

Table 3 summarises the trends in the development of a production base for computers in India over the last 25 years. This can be divided into four distinct phases.

3.1a Laboratory machines The first efforts in designing and building computers in India, as in the advanced countries, were made by institutions concerned with education and research. Credit-worthy and substantial though these efforts were for their time, they are significant today only in a historical perspective. Understandably, such efforts 


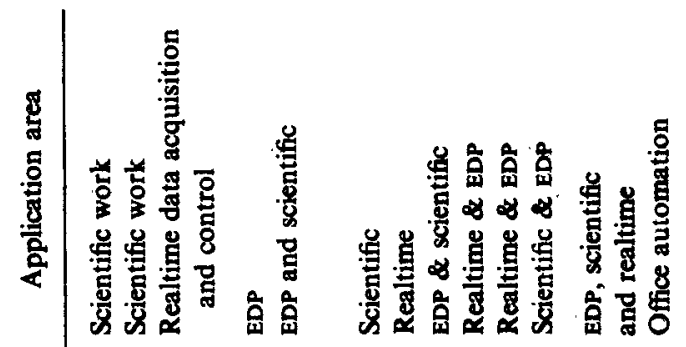

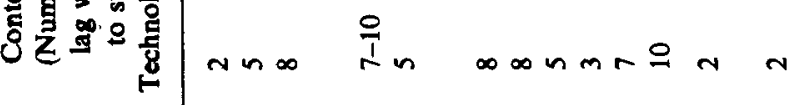

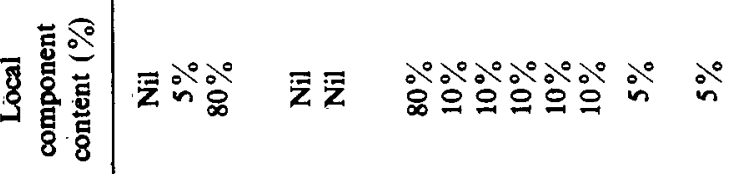

窇

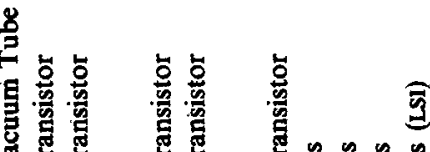

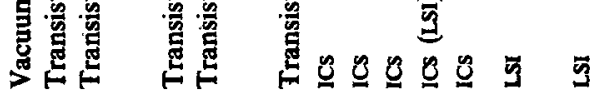

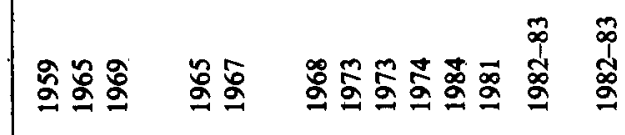

总总

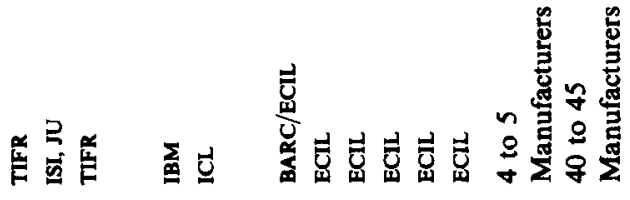

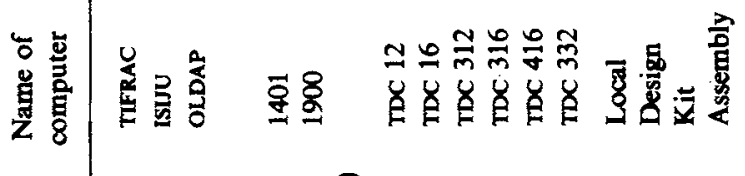

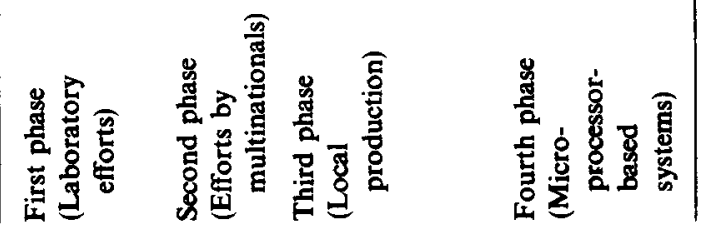


did not lead directly to any manufacturing activities. The main contribution of these early efforts was in the creation of a first generation of computer professionals in India.

3.1b Effort by multinationals The multinational companies attempted to establish themselves in the Indian market using two methods: (a) reconditioning (repair/replacement of worn-out or defective parts) of used machines imported into the country, and (b) local assembly using imported kits and sub-assemblies. These commercial programmes have been of little or no help in building up an indigenous capability in design and manufacture of computer systems.

3.1c Production based on local design and development Electronics Corporation of India Limited (ECIL) initiated a purely Indian effort for the development and production of computers. This can be considered to be the first genuine step towards the creation of a substantive design and production capability in India. The ECIL program, however, has suffered from several handicaps. The emphasis on exclusive dependence on local components in the early stages ruled out the feasibility of producing truly contemporary systems. The subsequent shift to the use of imported components helped to reduce the gap to some extent. Failure to realise the importance of advanced production techniques and stringent quality control measures resulted in the early machines being unreliable in operation in the field. In the early stages there were also inadequacies in software and systems support. All these factors resulted in considerable customer dissatisfaction with the ECIL systems. More recently, many of these shortfalls have been rectified and the performance of these systems has improved greatly. Nevertheless, EcIL's production effort continues to suffer from a high cost/performance ratio. This is partly due to the high cost of imported components because of the duties imposed, and to the failure on the part of ECIL to change its design and production technology fast enough to take advantage of cost/performance improvements in microelectronics technology.

3.1d Microprocessor-based machines A large number (about 50) of manufacturers are currently involved in the production of microprocessor-based computers. A few of these systems, notably those built by organisations with adequate technical competence and experience, or by technocrat entrepreneurs, are well designed and are suitable for a variety of non-trivial applications. These manufacturers also offer extensive and intensive software support. Table 4 summarises the features of a few of these computer systems. It is obvious from the table that these machines compare very favourably with their counterparts elsewhere in the world and can be depended upon for realtime, scientific and EDP applications in this range.

Many of the other manufacturers in this field are producing microprocessor-based systems which are primarily oriented towards office automation and the commerical data processing market. Modelled essentially on personal computers (machines with restricted capability that are intended to be used on a dedicated basis by a single operator) which have been successful in the advanced countries, these machines have proved to be quite successful here also. Very few among these systems, however, support realtime applications such as data logging and process control. These applications, in fact, are the ones of primary importance to our country.

Quite a few of the locally built microprocessor-based systems are aimed at wordprocessing type of applications. Most of these systems are only assembled here, out of semi-knocked-down or completely-knocked-down kits imported from various coun- 


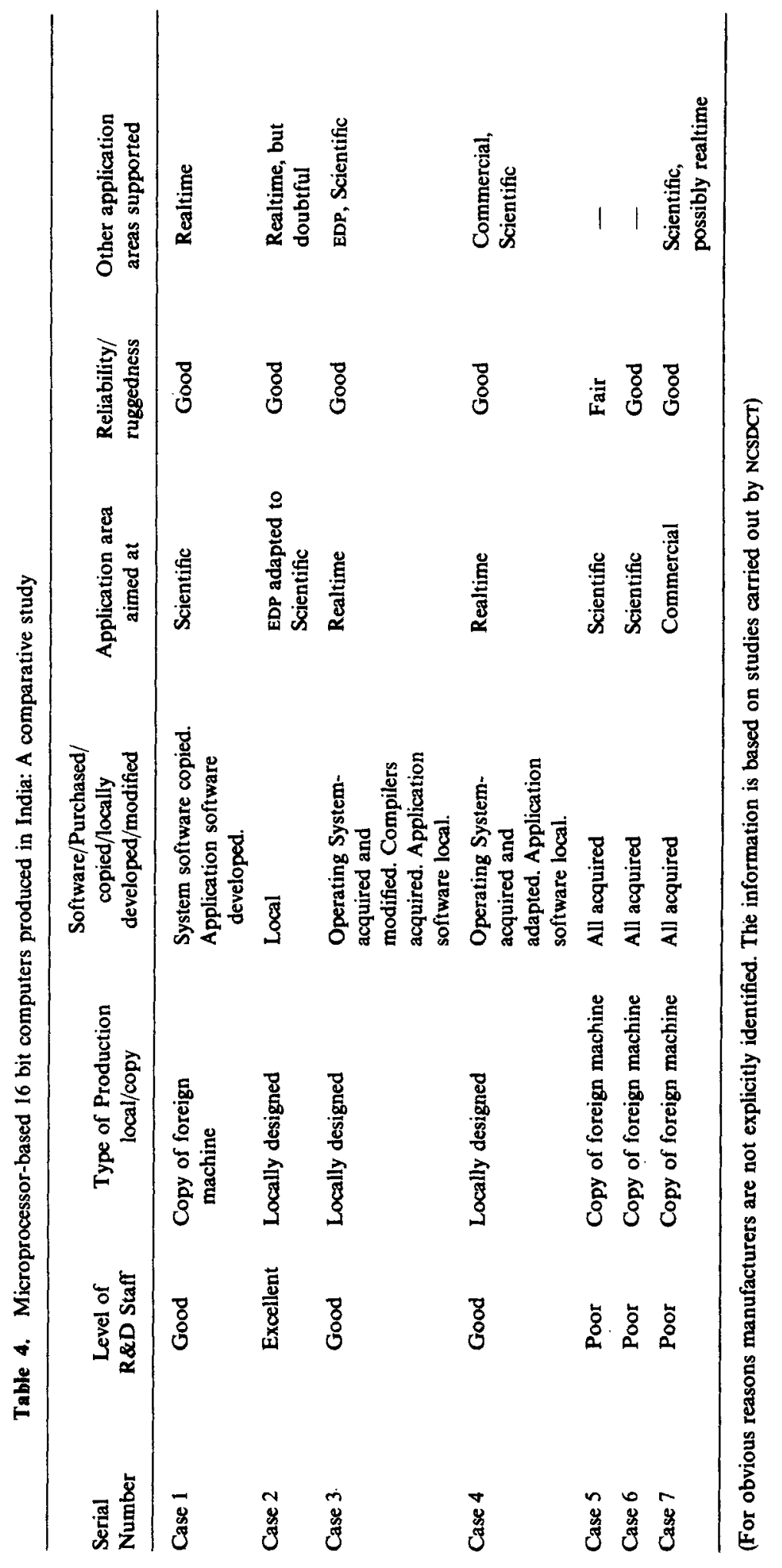


tries. Assembly from knocked-down-kits is a permissible operation but only as a first step in a phased manufacturing programme which leads eventually to substantial local manufacture. The real concern is that many of these so-called "manufacturing" programmes will never go beyond the first step of assembly from imported kits; it would be possible for them to change their identity after a few years and start kitassembly once again under another name for another product.

It should be useful to examine the reasons for this weakness in the Indian computer scene. Designing systems locally requires highly trained manpower and can be quite expensive. The risk factor in such design efforts is also quite high. Sophisticated equipment is required for production and this, in general, has to be imported. Heavy investment of capital can be cost-effective only if production can be sustained over a long period and at a reasonable volume. Kit assembly avoids the expense and the uncertainty in such a venture and is, therefore, a very attractive soft option.

The computer scene in India demonstrates that there is adequate competence in circuit, logic and systems design. It also demonstrates that our production technology requires improvement along many dimensions. But the main handicap that manufacturing efforts suffer from is that the infrastructure to support them-the (professional) components industry-is practically non-existent. With increasing levels of integration, the complexity of the IC chip is growing beyond imagination. As against the early IC chips which contained a few tens of components, today's LSI chip easily has several hundreds of thousands of components. The number of chips required for implementing a machine of any given level of complexity is therefore rapidly decreasing. There is also a corresponding decrease in the scope for logic and system design by the computer manufacturer; in fact, circuit, logic and system design activities have shifted from the computer manufacturer to the electronic device manufacturer. Consequently, the value added in the process of computer hardware manufacture has been decreasing very rapidly while the foreign exchange component of the finished product has been correspondingly increasing, in the absence of local chipmanufacturing capability.

Considering this and the fact that non-trivial contributions to circuit, logic and system design are possible only at the level of chip design, it is obviously very essential to establish local facilities for the design of Ic chips and for the production of the chips so designed.

The Semiconductor Complex Ltd. recently set up in Chandigarh is expected to manufacture chips of a restricted variety of limited complexity. However, looking to the future, design capability to undertake the design of chips of much greater complexity, and atleast limited fabrication capability to turn these designs into hardware, must be created in the country. We shall return to this issue and comment on it more in $\$ 5$. Apart from chip-making capability, it is essential to have multilayer printed circuit board making facilities and other related infrastructures. A well-integrated, long-term plan is needed to create these high-technology system building infrastructures in the country.

Electromechanical peripherals have also been a major problem. Copy adaptation of successful designs from other countries is possible for electronics systems, but fails completely in the case of electromechanical peripherals. This is because materials technology and process know-how are important to ensure that crucial components have the requisite dimensional stability and surface hardness which determine equipment life and long term reliability. Information regarding these is invariably a 
jealously guarded trade secret and it is impossible to obtain such information by examining the finished product. Know-how purchase therefore seems to be necessary in this field.

Some manufacturing capability has been built up in the country for making interactive terminals, data-entry terminals, floppy drives; typewriter/daisy-wheel output terminals, etc. A considerably more well-planned effort is needed to strengthen these activities, and also to undertake the manufacture of plotters, key-boards, tablets, and a variety of other input/output devices.

\section{$3.2 R \& D$ efforts in system building}

Most of the earlier applications of computers in India have been of the "numbercrunching" type and have used the computer merely as a stand-alone facility. Applications where a computer forms part of a larger system have been slow in identification and development. The main reasons are: (a) such systems require much greater efforts to incorporate into a service environment; and (b) they have in general to be designed on a custom basis. Physical realisation of such systems involves a variety of activities: systems analysis and design; implementation of interfacing hardware, appropriate systems software, and application software; and in some cases, even the design and building of the special purpose computers themselves. A number of such systems have nevertheless been designed in the country and successfully made use of.

Table 5 presents the salient features and other relevant details of some of these systems. All these efforts were initiated because of strongly felt needs in important areas. Special funding had to be provided to the respective organizations in most cases. The requirements were for complex systems. The developmental efforts invariably involved inter-institutional cooperation, in some cases extending to as many as five or six organisations. More significantly, these design efforts reflect the most important development in contemporary information technology-the coming together of computers and communication. All the examples listed in the table were development efforts intended to lead to quantity production. The impact of these efforts was thus significant even quantitatively. They were instrumental in the induction of computers into sectors which were not exposed to the computer culture earlier. This induction brought about not merely a quantitative increase in efficiency and productivity but also a substantial improvement in the quality of services available.

The development efforts in most of these cases were not, as is usually the case in India, confined to merely proving the feasibility of an idea but included translating the design into a production-worthy prototype which satisfied the technical and environmental specifications laid down for it. In fact, they extended to the transfer of know-how to the manufacturer, training the user in the various aspects of utilisation, maintenance and optimum exploitation of the system and, finally, bringing about the integration of the system into the operational environment in which it was expected to be used.

The environmental and ruggedisation requirements for (atleast some of) these systems were very stringent. A fallout from these efforts was, therefore, the establishment of an adequate production base for ruggedised digital systems. A very unique feature of these projects has been the extent of involvement of staff from the user agencies. Instead of being presented with a fiat-accompli (which is the case with imported systems), the user participated in the development effort and in all the 


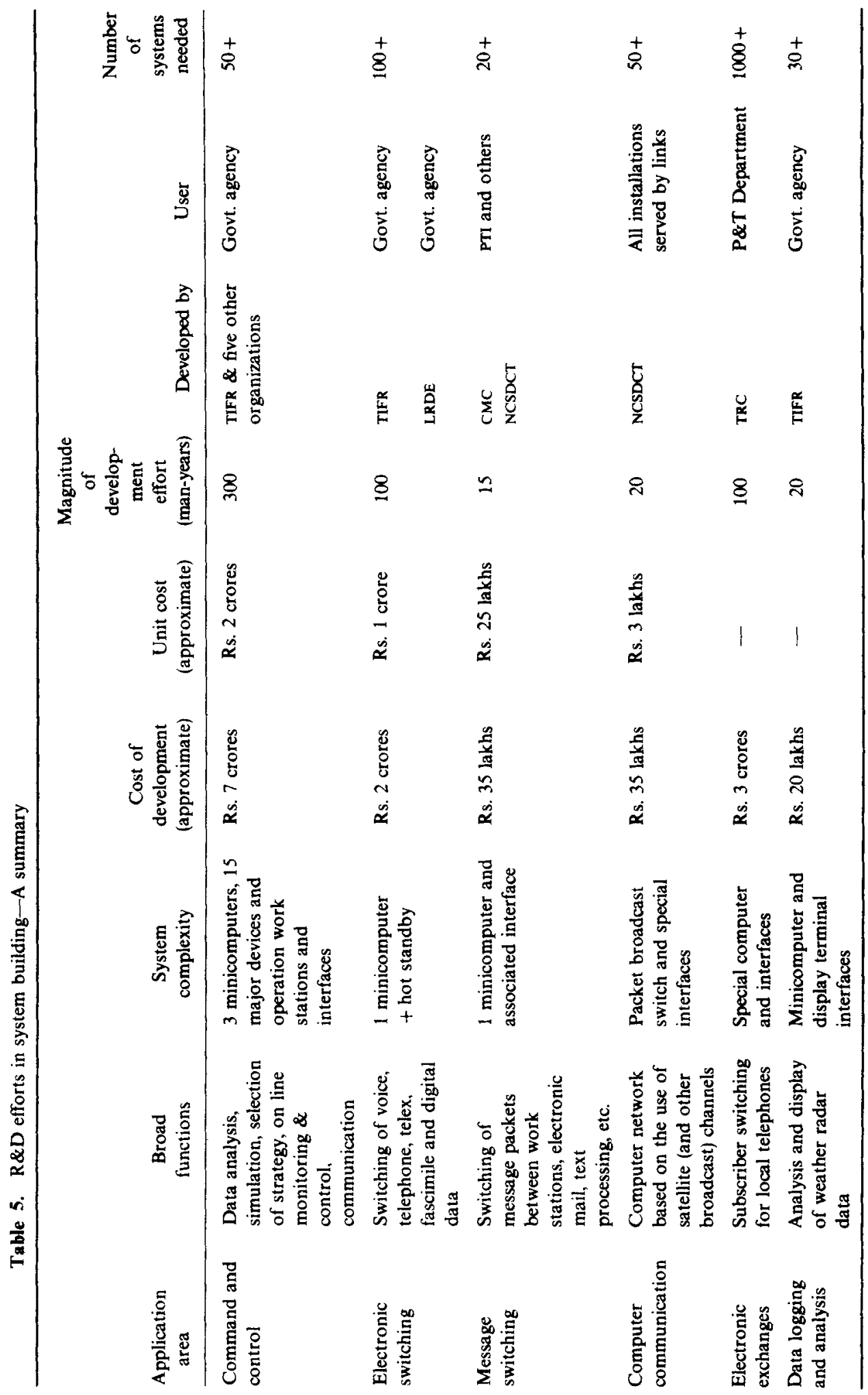


associated decision-making processes. This intimate involvement of the user, extending far beyond mere utilisation of the system facilitated the penetration of computer literacy into important sectors of government and industry.

At least two of these developmental efforts involved the development of specially designed powerful and versatile computers with a range of applications which extended far beyond the immediate purpose for which they were designed.

The value added in the process of system engineering in these cases has been quite high, the hardware costs being $25 \%$ or less of the total system cost. This demonstrates very clearly that system engineering for such complex applications is a viable and worthwhile activity in India, even if all subsystems have to be imported.

Manpower training has been another important, if indirect, fallout from such developmental efforts. Large numbers of computer engineers received sophisticated on-the-job training and practical experience in computer technology while working on these projects.

On the other hand, the main weakness of these efforts has been that many of these projects were undertaken as one-time efforts by organisations whose main interest did not necessarily lie in the concerned application areas. These organisations had to become involved in the projects because other organisations did not have the requisite expertise. The tasks being intrinsically challenging, there was no hesitation in taking them up. This meant, however, that there was no long-term continuity. It was not possible to retain in these organisations the competence acquired during the developmental effort for internal use, let alone for building further on it. Also, the heavy interinstitutional involvement and interaction that were necessary during the development of these systems had to be sustained without the aid of any formal frameworks or duly instituted mechanisms for such interaction. This meant that division of responsibilities and areas of accountability had to be evolved and adhered to, purely informally, on the basis of personal equations between the respective group leaders-a far from ideal mode of functioning. The high mobility of staff and the consequent shortage of manpower were the other handicaps that these efforts had to put up with. The absence of continuing programmes of activity in these areas meant that the staff involved could not evolve long term objectives and programmes of work. This denied continuity to their efforts and, hence, contributed to staff attrition.

These projects, nevertheless, succeeded in achieving their stated objectives. They have turned out to be very effective in inducting computers into vital areas of national activity which remained far outside the reach of commercially available, stand-alone, computers. The main lesson to be drawn from these successful efforts is that there is considerable scope in India for taking up customised system-engineering activities in a variety of important application areas, but, viable institutional frameworks to undertake such efforts on a long-term basis must be created in the country. This calls for much imagination, organisational skill, and leadership of high calibre.

\section{Manpower development}

Qualified manpower is the single most critical resource in the information technology area all over the world. This is especially true of India. For, not only is the manpower currently being developed in this field here small in quantity, but we also tend to lose a large percentage of the best of it through brain drain to the Western countries-mostly 
to the USA. Our strategies for manpower development in this extremely fast-moving field, therefore, should be closely integrated with creating challenging opportunities for work in order to hold these qualified persons in the country. We discussed at some length in the last section policies and programmes needed to create such opportunities for work for bright young people specializing in this field in India. In this section we shall consider briefly the programmes that are needed to promote computer literacy in general, and to create the manpower needed to cope with the design, engineering and building of information technology equipment and systems for our internal use and for export.

The manpower that is needed in this sector spans a very wide spectrum: from hardware and software technicians, to information system analysts, system designers, managers of production/implementation teams, and research and development scientists. In addition, we also need maintenance engineers and technicians, and marketing specialists. Currently in India we do not have a systematic educational and training progamme to produce the wide-spectrum of skilled manpower that is needed in this field. Except for the BEs, B.Techs, and M.Techs that IITs, Institutes of Science, and some universities train in a formal way in computer science and technology, most of the manpower that is actually employed in this area at present function after more or less superficial on-the-job training.

A more systematic manpower generation scheme must take into account the following components.

(i) Generation of fully qualified hardware and software scientists and engineers in computer science and technology: These persons would go through a formal educational programme in computer science and technology up to the bachelor's, master's, or doctoral level. After qualification they should be able to function as senior hardware and software engineers, systems analysts, and R\&D scientists in information technology.

(ii) Retraining of qualified application area specialists and first degree holders: Very large numbers of students who graduate with a first degree in science, commerce and other subjects with a reasonable exposure to mathematics, can be retrained to be efficient programmers. Analogously, persons with degrees in specialised engineering and technology areas can be trained to be qualified application area analysts and system designers. Currently such persons tend to drift into the software industrial market as entry-level programmers and coders. With proper training in the formal aspects of computer systems (hardware and software) they could be moulded into application area specialists so that their specialized formal backgrounds in the concerned application areas could be put to effective use.

(iii) Vocational training and extension training in information technology: Students who opt for vocational training at the secondary school level, and carefully selected secondary school drop-outs can be trained to be coders, computer operators, datapreparation personnel, and hardware technicians.

(iv) Training of public- and government-sector end-user groups: Most of the development-related activities in developing countries like India-for example, basic needs programmes, agricultural extension activities, transportation, energy generation and distribution, communication, and so on-are in the government and public sectors. The training of end-user groups in these sectors in computer usage and in understanding the potential of information technology in these sectors is of fundamental 
importance. Except for isolated short-term programmes run by Institutes of Management and similar organizations, in India at present there are no systematic educational/training programmes to upgrade the technological literacy of government departments/agencies and public sector organizations. At the service-level this absence of contemporary technological literacy-especially in information technologyconstitutes a serious hurdle to effective modernization of these services.

(v) Public education in information awareness: Public education in computer literacy and information awareness is of fundamental importance to India. A prerequisite to effective deployment of information technology in development-catalyzing applications is the awareness that "information" is an economic commodity. Bringing about this awareness both within the governmental sector and among the general public is an essential requirement for development.

To cope with the manpower shortage problem, in the last few years a large number of universities and teaching institutions have started computer science and computer application courses and post-B.Sc. diploma courses. Although in this.context there has been much discussion about curriculum development and related aspects, not enough critical analysis has gone into more basic issues: for example, the adequacy of these training programmes to meet the real needs, the facilities and the quality of staff available for teaching, the professional quality of persons who result from these programmes, the extent to which they are effectively being utilized for meaningful and productive activity, and so on.

The manpower shortage has inevitably given rise to a large number of commercial training establishments offering courses in computer programming. The training offered by most of them is of questionable professional quality. There is, hence, a need for a national level assessment procedure to test the competence of programmers turned out by such commercial establishments. The National Standard Test for Programming Competence (NSTPC) conducted by the Computer Society of India answers this need. Organized every year in practically every major city in the country, this test has been able to demonstrate the exceptionally poor quality of training offered by such "schools".

Facilities for extension training and continuing education are yet very poorly developed in the country. Perhaps the most systematic such part-time, in-service, educational programme available is the one conducted in Software Technology by the National Centre for Software Development and Computing Techniques (NCSDCT) in Bombay. There is an urgent need to organize similar courses in a large number of cities - especially in the non-metropolitan ones. Part-time courses that emphasize selfstudy and provide creative access to a good library and liberal computer time are perhaps of more value in a fast-moving technology like information technology, than degree and diploma courses for the vast majority of the field-level workers.

\section{Some issues in education and research}

\subsection{Education}

Some of the educational aspects have already been covered in a general way while discussing manpower development in the last section. Here we shall concentrate on two specific sets of issues: the first relating to the need for upgrading the information technology infrastructure for teaching engineering and technology courses, and the 
second relating to forward-looking research and development programmes in information technology that need to be encouraged in the teaching institutions.

Earlier, in $\S 1$, we saw that computers are beginning to be deployed in advanced Western countries in an all-pervasive manner as information-processing "engines" to support all kinds of activities. This applies equally to teaching and learning at all levels from primary and secondary schools on up to the college- and post-graduate-level education. The qualitative change that has been brought about in the learning environment is perhaps nowhere more significant than in engineering education. Imaginative and innovative deployment of microprocessor- and minicomputer-based workstations (to facilitate complex design projects), word-processing and document preparation facilities, and personal computers for student-level activities, all tied together in a distributed computing network with high bandwidth datacommunication channels has made it possible to extend the scope of professional education beyond what was imaginable hitherto. Using computer-aids, graphics facilities, microprocessor-controlled machine tools, instruments, other laboratory equipment, cameras, etc., students and other research personnel can carry out now in a learning environment programmes and projects that would have been unthinkable a decade ago. It is difficult to exaggerate the basic difference this kind of computationally rich environment makes to the training of engineers of all specializations-especially so, of mechanical, chemical, structural, electronic, and architectural engineers.

Sadly, in India computers in engineering institutes - even in high quality centres such as the IITs and the Institutes of Science-continue to function as 'number-crunching' devices used exclusively for numerical problem-solving. Engineering practices that underpin engineering education still continue in the pre-computer age. The engineering student is hardly ever confronted with the possibility of modernizing these engineering practices through the innovative deployment of microprocessor-based information technology tools. Computer-aided design, computer-aided draughting, computeraided engineering, computer-controlled machine tools, microprocessor-based field instruments for surveying, map-making, and so on, are not standard components of the educational environment in which an engineering student is taught and trained. Thus, our engineering institutes - even the very best of them-turn out professionals who are illiterates as regards the vast potential of information technology in enriching their own professional practices.

Enriching the information technology base of our engineering and technology education programmes is perhaps one of the most important steps that needs to be taken in India urgently. On this depends the possibility of modernizing the engineering and technology activities in our economy. To compete successfully in a technologically sophisticated world, our economy must also be technologically sophisticated; to achieve this the work environment and the workers must also be so. The precondition for these is an educational environment that sensitizes the students to the need for, and the potential of, technologically sophisticated tools and practices. Appropriate deployment of information technology in engineering education is the means to this end.

\subsection{Research}

Apart from theoretical areas in computer science and software technology, there must be a long-term, coordinated effort to promote R\&D activities of high quality in the 
following thrust areas of information technology: Ic technology; telecommunication technology; computer-aided design and engineering, including robotics; computer-aids to document preparation, printing and publishing; and knowledge-based expert systems. We shall consider very briefly what is possible to be undertaken in each of these areas in the country.

We have already considered in $\$ 3$ the need for developing design centres and capability to take up the design of customized LSI, and later on VLSI, chips. Some capability must also be developed to convert these designs into physical chips. It has been claimed that the Semiconductor Complex Ltd (SCL) would function as a silicon foundry to fulfil this need. But there is a good case to be made for establishing a national-level silicon foundry which would cater to design sophistication an order of magnitude better than what the SCL has been set up to cope with. Education and training in LSI and vLSI design must aim to develop expertise much in advance of the production base that has been created through purchased know-how and technology. At least a pilot-level fabrication facility is a necessity to achieve this.

Our earlier discussions emphasized the far-reaching changes that have been brought about in information industry through the convergence of computing and communications. In this context a number of technological issues have arisen for active study and exploration. A variety of computing techniques in digital electronic switching are being investigated. Two thrust areas that are emerging in this interdisciplinary domain of computing and communications are: local area networks (LANS) and "intelligent" private branch exchanges (PBXs). In both cases the objective is to develop an integrated digital communication facility capable of handling voice, text, data, graphics, and video in one physical framework. The Government of India is making a major investment to create a Centre for R\&D in digital switching and stored-program electronic exchange technology. It is to be hoped that the activities of this Centre would reach into, and make an impact on, the education and training programmes of our major engineering institutes.

The Government of India has initiated with assistance from UNDP a training programme in graphics and computer-aided design. But this programme is very modest in its scope and certainly does not meet the full needs of the country. In fact, as we argued earlier, CAD and CAE are already well-enough developed as technologies to be integrated into engineering education in India immediately. Any specialized centres that are set up should really function as advanced $R \& D$ centres and contribute to the growth of these technologies. Involvement in robotics technology, at least at the R\&Dlevel, is also an important need for us in India.

Computer-assisted text-processing, document preparation and publishing are of very great relevance to India. Upgrading the average level of literacy of the population of this country is a pre-requisite to success in modernizing our society and improving the productivity of our economy. The plurality of languages and scripts in India make the traditional hot-metal technology extremely unviable economically for large-scale printing and publishing. This is all the more true if printing and publishing are to be undertaken on a decentralized basis at the local community level. Computer textprocessing, composition, and off-set printing offer possibilities which are very rich in creative potential. But before such technologies could be put to work at the production level to support mass-literacy programmes, a large number of R\&D problems have to be solved: for example, standardization of scripts and design of fonts, text-processing 
software development for use with these scripts, input-output equipment design and manufacture, and so on. Engineering and technology institutes can again play a seminal role in all these $R \& D$ efforts.

Fifth generation computer technology, as we saw earlier, is causing much discussion and generating much excitement among the computer scientists and technologists of the advanced countries. Whether India can or should get involved in this technology at the R\&D level at this stage is a moot point. The hardware aspects of this technology would undoubtedly be far outside the scope of what is feasible even at the laboratorylevel in India at present. However, the knowledge-engineering aspect of this technology should not be outside our capability to explore and experiment with. Knowledge-based expert systems for well-defined application areas are already being commercialized. It is being predicted that one of the fastest growing uses of artificial intelligence (AI) would be in biomedical application through the use of expert systems. The technological as well as the computer science aspects of $\mathrm{Al}$ and expert system studies have considerable scope for enriching our engineering education and training.

Although we have not said anything about software technology explicitly, it should be clear that software underpins in an essential way all the information technology specializations we have talked about so far. Acquiring advanced software expertise should become an integral part of engineering education much as acquiring expertise in advanced mathematics is looked upon as a necessity now.

\section{Concluding comments}

We have discussed in this paper in some detail the current thrust areas in information technology and the far-reaching social, economic, and industrial changes that this technology is bringing about in advanced industrialized countries. The coming together of computing and communications has been the single most important cause for the revolutionary impact of information technology.

In this background our main thesis in this paper may be summarized as follows. In India we have so far been preoccupied with developing computer technology to build computers to function as stand-alone "number-crunchers" or commercial dataprocessing machines. Our industrial capability even to accomplish this is still fragmented. We have not realized fully, however, that the future of computer technology lies in its integration with communication technology. A prerequisite for this integration is the modernization of communication technology in this country and building up a viable infrastructure for digital data transmission. Information technology, which has as its base the integration of computing and communication, is of vital importance to India. The mastery of this technology in all its ramifications involves building up our strength in a whole variety of sub-technologies such as: microelectronics, lasers, fibre-optics, displays, digital communication, CAD-CAE, expert systems, etc., and, underpinning all these, software technology. While formulating policies and programmes and creating centres to build up our strength in all these specializations, it is essential to ensure that the level of information technological sophistication that supports our engineering education and training is also correspondingly improved. Right now this level is very poor. We have pointed out various ways in which the support of this technology to education could be improved. 


\section{References}

Kahn R E 1983 IEEE Spectrum 20: 36-41

OECD 1982 Information activities, electronics and telecommunication technologies: Impact on employment, growth and trade, Vol. 1 of Information, Computer, Communications Policy, No. 6, OECD, Paris Porat M 1977 The information economy, U. S. Department of Commerce

United Nations 1971 The application of computer technology for development 